\title{
New Results in Optical Modelling of Quantum Well Solar Cells
}

\author{
Silvian Fara, ${ }^{1}$ Paul Sterian, ${ }^{2}$ Laurentiu Fara, ${ }^{2}$ Mihai Iancu, ${ }^{1}$ and Andreea Sterian ${ }^{2}$ \\ ${ }^{1}$ IPA SA, Calea Floreasca 169, 014459 Bucharest, Romania \\ ${ }^{2}$ University Politehnica of Bucharest, Splaiul Independentei 313, 060042 Bucharest, Romania
}

Correspondence should be addressed to Andreea Sterian, andreea_sterian@physics.pub.ro

Received 6 October 2011; Accepted 24 January 2012

Academic Editor: Bhushan Sopori

Copyright ( 2012 Silvian Fara et al. This is an open access article distributed under the Creative Commons Attribution License, which permits unrestricted use, distribution, and reproduction in any medium, provided the original work is properly cited.

\begin{abstract}
This project brought further advancements to the quantum well solar cell concept proposed by Keith Barnham. In this paper, the optical modelling of MQW solar cells was analyzed and we focussed on the following topics: (i) simulation of the refraction index and the reflectance, (ii) simulation of the absorption coefficient, (iii) simulation of the quantum efficiency for the absorption process, (iv) discussion and modelling of the quantum confinement effect, and (v) evaluation of datasheet parameters of the MQW cell.
\end{abstract}

\section{Background}

Quantum well (QW) photovoltaic cells, third-generation solar cells, were proposed in 1990 by the research group of Professor Barnham [1] aiming at extending the spectral response and at increasing the photocurrent.

The quantum well solar cell $(\mathrm{QW})$ is a $\mathrm{p}$-i-n structure having quantum wells built in the intrinsic. Doped regions on each side will produce an electric field perpendicular to the layers of quantum wells. It is also possible to have induced electric fields, because of the piezoelectric effects. These fields are induced by the intensities from the semiconductor layers, because of the disparity between network constants [2].

The multiple quantum well (MQW) solar cell is a system that contains a layer in which the carrier assemblies comply quantum rules in connection with layers in which the carrier assemblies are performing classical, and its modelling is conducted on two-dimensional levels [3]:

(1) quantum level in which one computes the energy spectrum of the electron and the absorption coefficient of the MQW;

(2) macroscopic level in which one studies the transport of charge carriers in a similar manner to the conventional p-i-n diode [4]. The reflection of light is brought considering MQW cell a pseudohomogeneous medium. This combination of quantum and classical elements used in modelling of MQW solar cell justifies the name of hybrid given to the model of MQW solar cell. An example of application of this hybrid model (HM) [5] is the case of solar cell based on a ternary alloy semiconductor $\mathrm{A}_{x} \mathrm{~B}_{1-x} \mathrm{C}$ $\left(\mathrm{Al}_{x} \mathrm{Ga}_{1-x} \mathrm{As}\right)$ which has the lowest $\mathrm{BC}$ band gap equal with zero and achieve the greatest value $(x=1)$ for the AC semiconductor band gap.

In Figure 1 are graphically represented the transmittances and energetic levels in the MWQ system as a result of the transport matrix algorithm [6]. The proper values from Figure 1(a) and resonances from Figure 1(b) are identical and mutually confirmed. The levels represented in Figure 1(a) are obtained by applying Kramer's rule, while the transmittances represented in Figure 1(b) are calculated via the transfer matrix. It is noted that a large variation of alloy composition $x$ does not determine significant changes in position of the first level from the quantum wells, which means that there is a weak dependence between short-circuit current and the ternary alloy composition. Each curve in Figure 1(b) is calculated in 104 points in less than a minute.

Figure 2 shows the geometry of an MQW solar cell in the HM hybrid model. This model allows determining the configuration that leads to maximum conversion efficiency. This layer configuration can further be designed, by using the transfer matrix method and the properties of the real materials. In other words, starting from a hypothetic layer system, the HM model allows optimization of the cell 


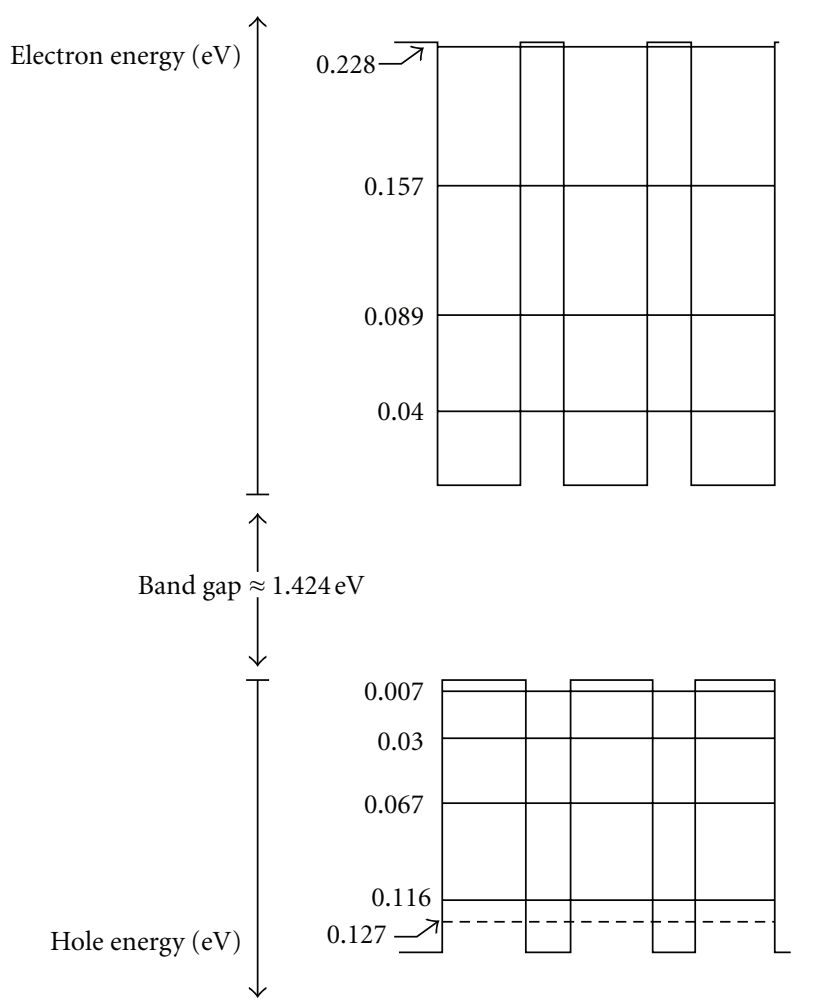

(a)

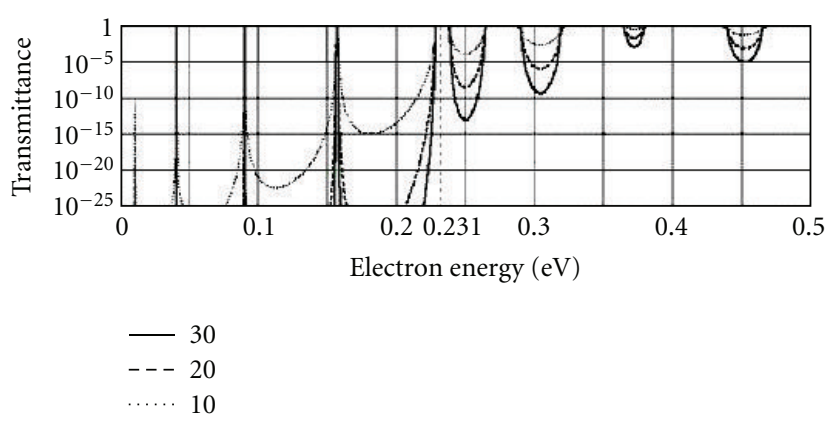

(b)

Figure 1: (a) Schematic representation of levels in the valence bands and conduction for the MQW system $\mathrm{Al}_{0.3} \mathrm{Ga}_{0.7} \mathrm{As} / \mathrm{GaAs}_{\mathrm{A}}$ containing 30 quantum wells. The corresponding level for the heavy gaps is shown with dotted line. (b) Transmission coefficient based on the electron energy for the same system. The curves parameter is the number of quantum wells.

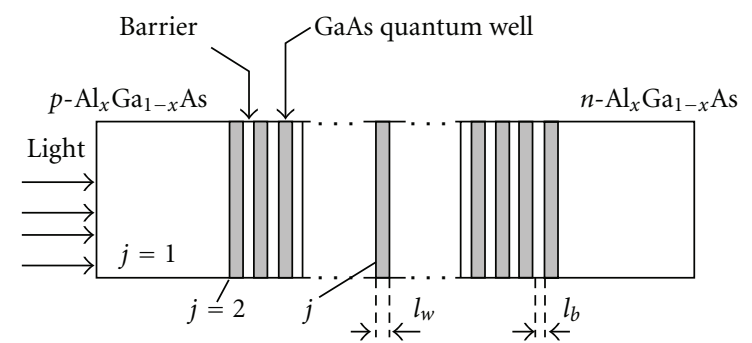

Figure 2: Geometry of a solar cell in the HM hybrid model.

configuration in order to obtain maximum output electrical power, for a certain state of illumination [4].

The HM model may have the capability to evaluate the performances of the MQW cell. These are represented by the shape factor of cell

$$
F_{f}=\frac{V_{m} I_{m}}{V_{\mathrm{CD}} J_{\mathrm{SC}}} \text { and conversion efficiency } \eta=\frac{V_{m} I_{m}}{\int G_{0}(\lambda) d \lambda}
$$

where $V_{m}$ and $I_{m}$ are the operation point coordinates when the power supplied in the load is maximum.

\section{Modeling and Simulation of Refraction Index and Reflectance}

Investigation of electric field effects on the refraction index of MQW solar cells can be achieved by calculating the absorption coefficient [7]. In the case of solar cells with quantum wells was introduced the hypothesis of an electrostatic field generated by the load [8]. For this reason, it is expected a nonvarying change in the refraction index. Based on the results obtained by Barnham, it should be noted that the quantum wells from the solar cells of this type are designed to use the spectrum region, with the possibility of generating particles in those quantum wells. For the refraction index of the solar cell with quantum wells it was used the following expression:

$$
n_{2}=n=\sqrt{1+\frac{E_{d}}{E_{o}}+\frac{E_{d}}{E_{o}^{3}} E^{2}+\frac{\eta}{\pi} E^{4} \ln \left(\frac{2 E_{o}^{2}-E_{g}^{2}-E^{2}}{E_{r}^{2}-E^{2}}\right)} .
$$

The parameters are $E_{g}=1.6729 ; E_{r}=1.4235 ; E_{o}=2.6+$ $0.7 E_{r} ; E_{d}=F / E_{o}$ and $\eta=\pi E_{d} /\left(2 E_{o}^{3}\left(E_{o}^{2}-E_{r}^{2}\right)\right)$.

The simulation results for the refraction index depending on the photon energy are represented in Figure 3.

The index of refraction model can be used to explore the relation between the index of refraction and reflectance. To achieve this, the refraction index model must be combined with the Fresnel relations, thus allowing the finding of the 


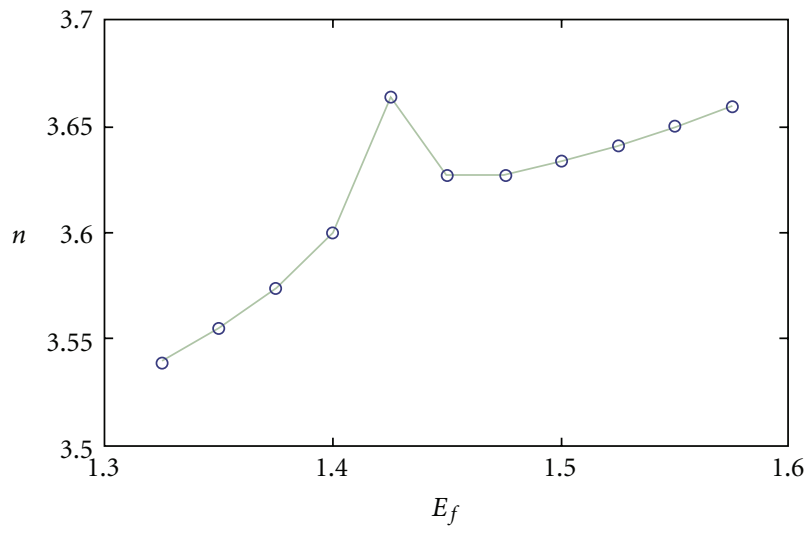

FIGURE 3: The refraction index of the cells with quantum wells depending on the photon energy.

losses caused by reflection of the quantum wells structure. The $R$ reflectance of the solar cell can be calculated using a Fresnel-type relation [9]

$$
R=\frac{r_{1}^{2}+r_{2}^{2}+2 r_{1} r_{2} \cos 2 \theta}{1+r_{1}^{2} r_{2}^{2}+2 r_{1} r_{2} \cos 2 \theta}
$$

where

$$
r_{1}=\frac{n_{0}-n_{1}}{n_{0}+n_{1}} ; \quad r_{2}=\frac{n_{1}-n_{2}}{n_{1}+n_{2}} ; \quad \theta=\frac{2 \pi \pi_{1} d_{1}}{\lambda} .
$$

The following notations were introduced: (i) $n_{0}$ the refraction index of the incident environment; for air $n_{0}=1$;

(ii) $n_{1}$ the refraction index of the antireflecting coating;

(iii) $n_{2}$ the refraction index of the under layer (the solar cell with quantum wells).

Thickness $d_{1}$ of the antireflecting coating can be determined by minimizing the last relation (5). It was noted that this value is approximately $600-650 \mathrm{~nm}$, for the minimum reflection.

It can be evaluated the effect of the quantum well number on the index of refraction and on the reflection losses so the optimal number of the quantum well for the structure could be calculated [10].

In Figure 4 are the results of the optical simulation of solar cells with quantum well (based on relations (3)-(4)), in the from of dependence on reflectance $R$, depending on the wavelength for different thicknesses $d$ for the antireflecting coating; were considered two cases of antireflecting coating $\left(n_{1}=2.4-\mathrm{TiO}_{2}\right.$ and $\left.n_{1}=1.4-\mathrm{SiO}\right)$. Results from model are consistent with experimental results obtained. The reflectance model can be used to determine the variation effects of quantum well number on the index of refraction.

The simulation of refraction index and reflectance of the solar cells with quantum wells have been made with the Octave software, version 3.02.

The cell reflectance can be calculated using the refraction indices of $\mathrm{GaAs}$ semiconductor and of the $\mathrm{Al}_{0.3} \mathrm{Ga}_{0.7} \mathrm{As}$ alloy (obtained by filtering the experimental data [11].

$$
n_{\text {GaAs }}= \begin{cases}\frac{3.24123-(4.8304085 / \lambda)+\left(2.82482 / \lambda^{2}\right)-\left(0.769037 / \lambda^{3}\right)+\left(0.08198 / \lambda^{4}\right)}{1-(1.5308 / \lambda)+\left(0.9123972 / \lambda^{2}\right)-\left(0.2508648 / \lambda^{3}\right)+\left(0.026769 / \lambda^{4}\right)}, & \text { if } 0.325<\lambda \leq 4, \\ \frac{2.8434068-(1.8916996 / \lambda)+\left(0.4189801 / \lambda^{2}\right)-\left(0.0308637 / \lambda^{3}\right)}{1-(0.682372 / \lambda)+\left(0.154593 / \lambda^{2}\right)-\left(0.01159 / \lambda^{3}\right)}, & \text { if } 0.2 \leq \lambda \leq 0.325 .\end{cases}
$$

In (5) $\lambda$ is expressed in $\mu \mathrm{m}$. The refraction index of ternary alloy $\mathrm{Al}_{x} \mathrm{Ga}_{1-x} \mathrm{As}$ is calculated using the same translation procedure of the axes as in the case of the absorption coefficient:

$$
\begin{array}{r}
n_{\mathrm{Al}_{x} \mathrm{Ga}_{1-x} \mathrm{As}}(\lambda)=\left[1.05-0.53 x+0.09 x^{2}\right] n_{\mathrm{GaAs}}\left(\lambda_{x}\right) \\
\text { with } \lambda \text { in } \mu \mathrm{m} .
\end{array}
$$

To minimize the reflection losses the solar cells are frequently coated with antireflecting coating (ARC).

In Figure 5(a) are the values calculated for the four refraction indices listed according to the wavelength. The MQW layer was considered to consist of 30 quantum wells of $\mathrm{GaAs}$ of $20 \mathrm{~nm}$ width separated by barriers $\mathrm{Al}_{0.3} \mathrm{Ga}_{0.7} \mathrm{As}$ with width of $10 \mathrm{~nm}$.

In Figure 5(b) are summarized the results of reflection losses for the various thicknesses of the antireflecting coating. In the absence of ARC, reflection is an important mechanism of losses exceeding $30 \%$ on the spectral range in which the cell absorbs. The other curves show that it is possible to reduce losses through reflection by covering with an antireflecting coating of appropriate thickness.

\section{Modelling and Simulation of Absorption Coefficient}

In applications related to calculating the conversion efficiency of solar cells, but also in other applications, the coefficient of absorption (the absorbance) is practically described by continuous functions. For GaAs, dropping from the experimental data [12] was determined the following function that approximates the acceptable rate of absorption:

$$
\begin{gathered}
\alpha_{\text {GaAs }}(\lambda)= \begin{cases}e^{F_{1}(\lambda)}, & 0.7<\lambda \leq 0.88, \\
e^{F_{2}(\lambda)}, & 0.24<\lambda \leq 0.7, \\
e^{F_{2}(0.24)}, & 0<\lambda \leq 0.24, \\
0, & \text { otherwise },\end{cases} \\
F_{1}(\lambda)=-0.7863+5.3115\left[1+\operatorname{erf}\left(-\frac{\lambda-0.84291}{0.038}\right)\right],
\end{gathered}
$$






FIGURE 4: Simulation of the reflectance for a solar cell with QW structure, for a $\mathrm{SiO}$ antireflecting coating.

$$
\begin{aligned}
F_{2}(\lambda)= & -447.432+4201.2 \lambda^{2}+6835.128 \lambda^{2} \ln \lambda \\
& -3781.193 \lambda^{3}+\frac{3.9049}{\lambda^{2}} .
\end{aligned}
$$

In Figure 6(a) is graphically represented the absorption coefficient for GaAs calculated with the algorithm from [13] for different compositions of the alloy.

In Figure 6(b) are graphically compared the absorption coefficients for $\mathrm{GaAs}, \mathrm{Al}_{0.5} \mathrm{Ga}_{0.5} \mathrm{As}$, and MQW system. It is noted that with increasing energy the absorption coefficient from MQW system increases in steps; this is because of the quantifying of the density of states in confinement of the carriers' direction.

Absorption coefficient $\alpha_{x}(\lambda)$ of the $\mathrm{Al}_{x} \mathrm{Ga}_{1-x}$ As alloy is generated from the absorption coefficient of the GaAs: $\alpha_{x}(\lambda)=\alpha_{0}\left(\lambda_{x}\right)$ ( $h$ is Planck constant, $c$ is the speed of light, $a=0.62$ and $b=0.5[13])$

$$
\lambda_{x}=\frac{h c}{(h c / \lambda)-E_{g}(x)+E_{g}(0)+\alpha\left[(h c / \lambda)-E_{g}(0)\right]^{b} x} .
$$

\section{Increasing Quantum Efficiency of the QW Solar Cells}

4.1. Simulation of the Quantum Efficiency of QW Solar Cells by Using a Semiquantum Model. The analyzed model uses the transport equation of $\mathrm{Al}_{x} \mathrm{Ga}_{1-x}$ As quantum well solar cells, where $x$ represents the Aluminium concentration. We considered the results obtaining by Hutchby and Fudurich [14], Connolly in his doctoral thesis [15], and Barnham's research group [16].

The model used the transport equation of $\mathrm{Al}_{x} \mathrm{Ga}_{1-x} \mathrm{As}$ solar cells. The expression of the quantum efficiency is given by

$$
\mathrm{QE} \cong \frac{\alpha k(\alpha-S)}{\left(k^{2}-\alpha^{2}\right)(S \sinh (k z)-k \cosh (k z))} \cong \frac{\alpha-S}{\alpha^{2}(S-1)} .
$$

It is introduced the parameter $S$ of the boundary condition on the surface. It is resulted $S \approx 2 \varepsilon f, \alpha=$ spectral absorption coefficient, $\varepsilon_{f}=$ effective electric field due to the minoritary carriers in the band.

The simulated results are presented in the Figures $7(\mathrm{a})$ and $7(b)$.

From the analysis of the data obtained, one can draw the following comments:

(i) quantum efficiency increases with any increase in $\lambda$, reaching significant values of maximum $90 \%$, in the case of large diffusion wavelength;

(ii) quantum efficiency increases with any increase of $z$ and $\varepsilon_{f}$, respectively.

4.2. Quantum Confinement Effect. In order to find ways for increasing efficiency through the simulation of nanostructured solar cells (QW), we have used a mathematical model for the quantum efficiency of the transitions between the resonant levels (in GaAs) and another one for the quantum efficiency of the transitions between the confining levels (in $\left.\mathrm{Al}_{x} \mathrm{Ga}_{1-x} \mathrm{As}\right)$ [17].

In the case of resonant levels, quantum efficiency of the absorption process is given as follows [18]:

$$
\mathrm{QE}_{\lambda}=\frac{8 \pi^{2} e^{2}}{c \hbar \varepsilon_{0} \varepsilon_{r w}}\left[\left(1-\frac{\sin ^{2} i}{4 \varepsilon_{r w}}\right)+\frac{t_{w}^{2}}{L^{2}} \frac{\sin ^{2} i}{4 \varepsilon_{r w}}\right],
$$

where $\alpha$ is prism angle, $i$ is incidence angle, $\varepsilon_{r}$ is relative permittivity, and $n$ is confinement level of quantum efficiency.

For transitions between the confining levels, the quantum efficiency is given by

$$
\mathrm{QE}_{\lambda_{n}}=\frac{4096 e^{2}}{\pi^{2} c \hbar \varepsilon_{0} \varepsilon_{r w, b}^{2}} \frac{t_{w, b}^{2}}{L^{2}} \frac{n^{2} \sin ^{2} i}{\left(4 n^{2}-1\right)^{4}} .
$$

In expressions (10) and (11), index $w$ refers to GaAs, and index $b$ refers to $\mathrm{Al}_{x} \mathrm{Ga}_{1-x}$ As.

For GaAs one obtains the curves of quantum efficiency of the transitions between the resonant levels (see Figures 8(a) and $8(\mathrm{~b})$ ) and between the confining levels, depending on the prism refraction index and on the incidence angle of the ray that falls on the prism, for $\alpha=\pi / 6$ and $\alpha=2 \pi / 3$. Similarly one obtains the quantum efficiency, for $\mathrm{Al}_{x} \mathrm{Ga}_{1-x} \mathrm{As}, N p=$ 1.5 ( $N p=2$ resp.), $\alpha=\pi / 6$ and $\alpha=2 \pi / 3$, depending on the quantity of Aluminium.

From the analysis of the results, one can conclude the following.

(i) The quantum efficiency of the absorption process for nanostructured (quantum) solar cells is higher for a larger range of wavelengths, in comparison to the semiquantum solar cells.

(ii) Although the quantum efficiency of the absorption on the confining levels is very low, the appearance of electrons in the gap greatly increases the photocurrent through photoassisted tunnelling.

(iii) Monitoring the operating parameters (processor loading, memory used, network traffic, etc.) of the cluster (which allowed a large volume of computations) was done with the help of the Ganglia application. 


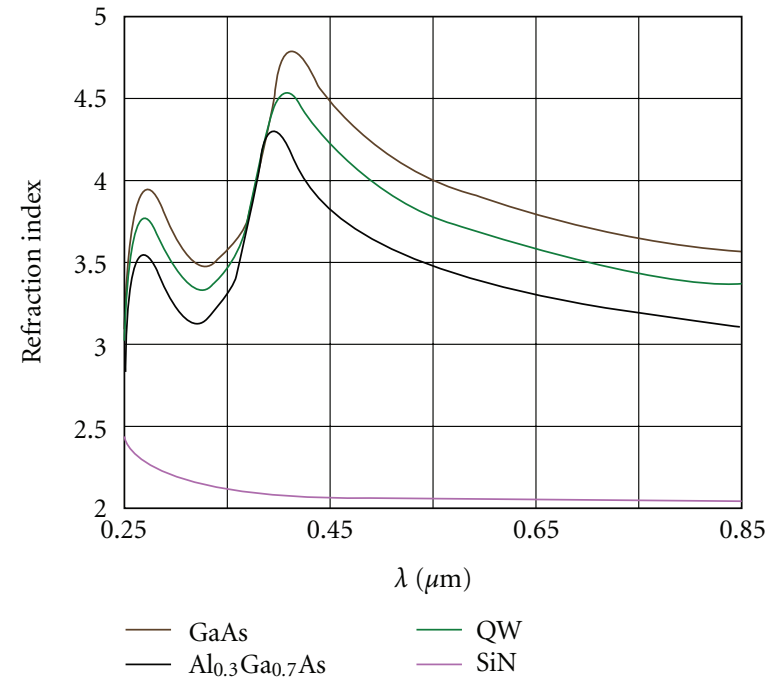

(a)

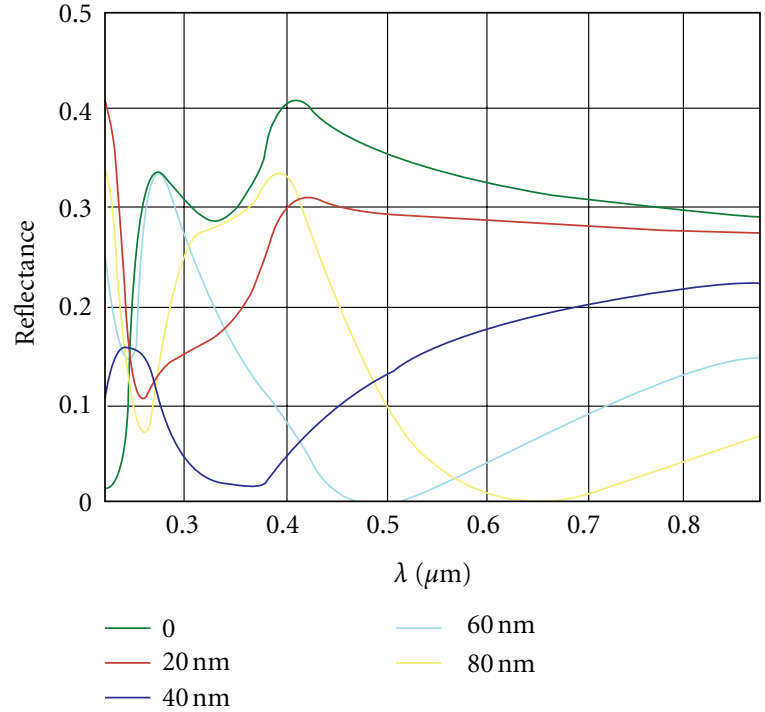

(b)

FIGURE 5: (a) The refraction index for the materials involved in constructing a MQW cell. (b) Spectral reflectance of the MQW cell for different width $(\mathrm{nm})$ of the antireflecting coating. The $\mathrm{HM}$ model was run for $\mathrm{GaAs} / \mathrm{Al}_{0.3} \mathrm{Ga}_{0.7} \mathrm{As}$ with $N_{w}=30, l_{w}=20 \mathrm{~nm}$ and $l_{b}=10 \mathrm{~nm}$.

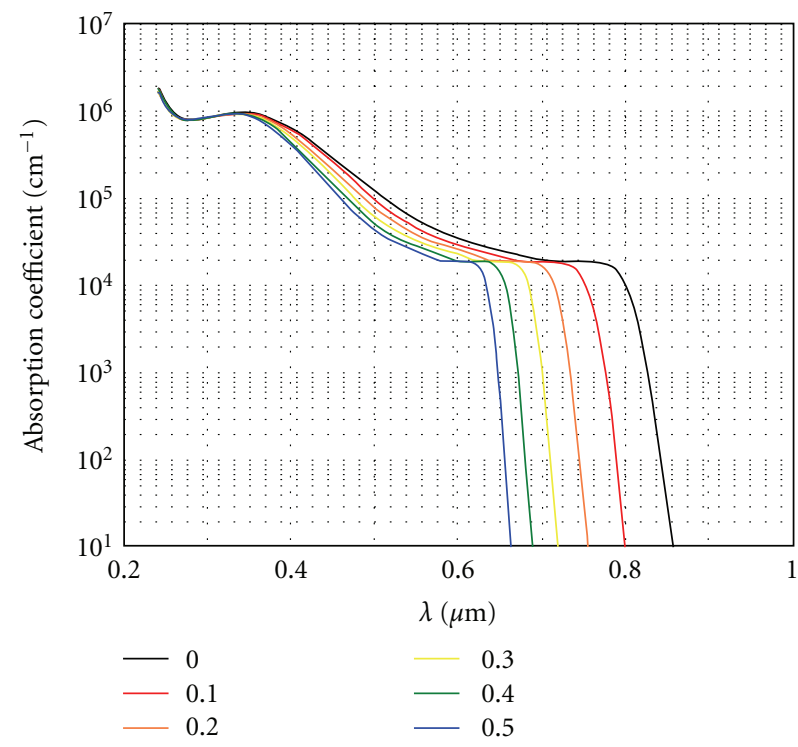

(a)

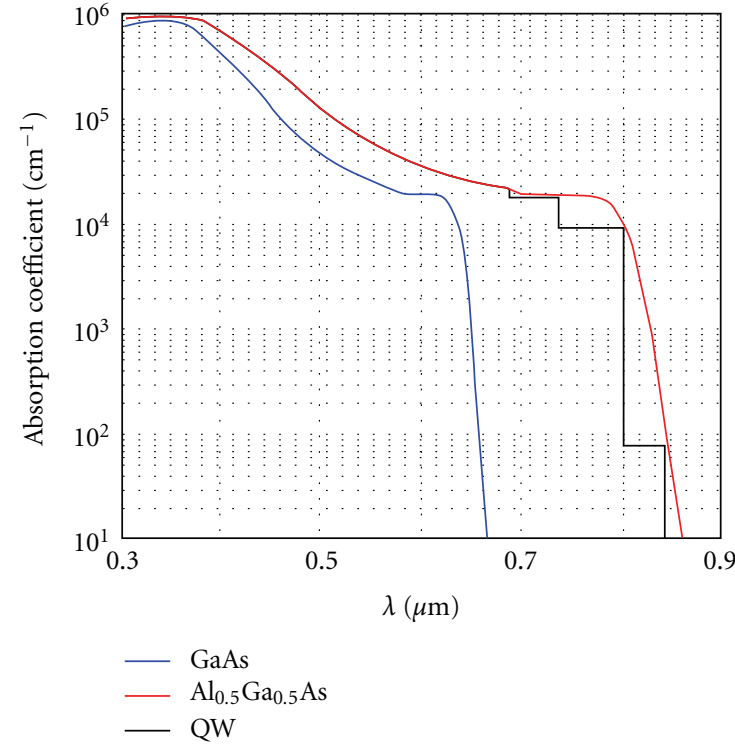

(b)

Figure 6: (a) Absorption coefficient of $\mathrm{Al}_{x} \mathrm{Ga}_{1-x} \mathrm{As}$ depending on wavelength; $x$ is the curves parameter. (b) Absorption coefficient in GaAs crystal; the ternary compound $\mathrm{Al}_{0.5} \mathrm{Ga}_{0.5}$ As is calculated using axes translation in MQW system.

\section{The Results Obtained during Simulation of the Cell Parameters}

In Figure 9, for the cell parameters $N_{w}=30, l_{w}=20 \mathrm{~nm}$, and $l_{b}=10 \mathrm{~nm}$ are summarized the calculation results of the conversion efficiency. In Figure 9(a) are represented the current-intensity characteristic with the power dissipated by the cell in the external circuit. Hence the main parameters of the cell are $J_{\mathrm{SC}}=48.5 \mathrm{~mA} / \mathrm{cm}^{2}, V_{\mathrm{CD}}=0.886 \mathrm{~V}, F_{f}=0.86$, and $\eta=0.371$. The numerical values are closed to those reported in the literature $[19,20]$. As for the conventional cell with a $\mathrm{p}-\mathrm{n}$ junction the maximum possible efficiency is estimated at 34\% [3]. The result nor confirms nor invalidates that the insertion of MQW in the space-load region improves the conversion efficiency.

Figure 9(b) shows the conversion efficiency dependence on the antireflecting coating depth. It can be noted that in the ideal case, when the cell reflectance is neglected, the MQW 

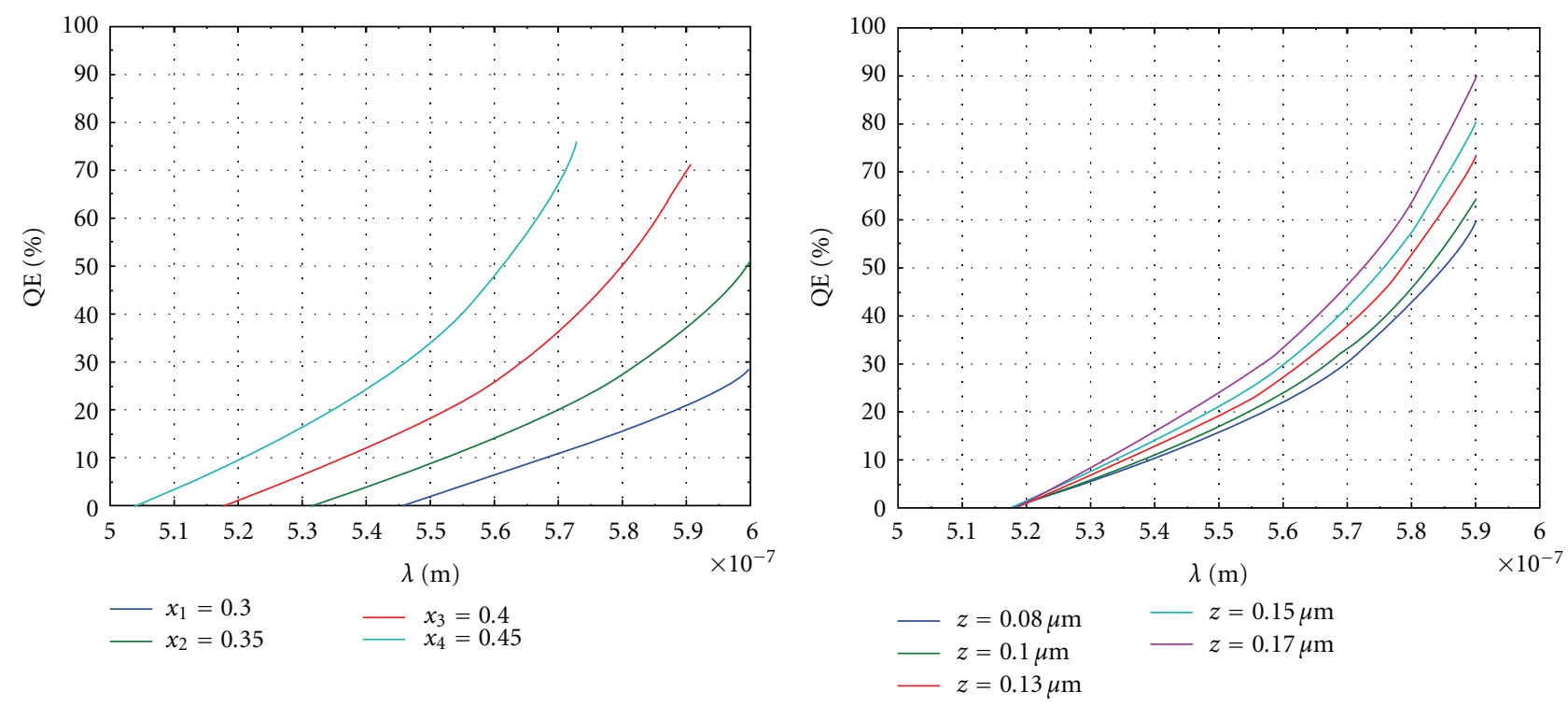

(a)

(b)

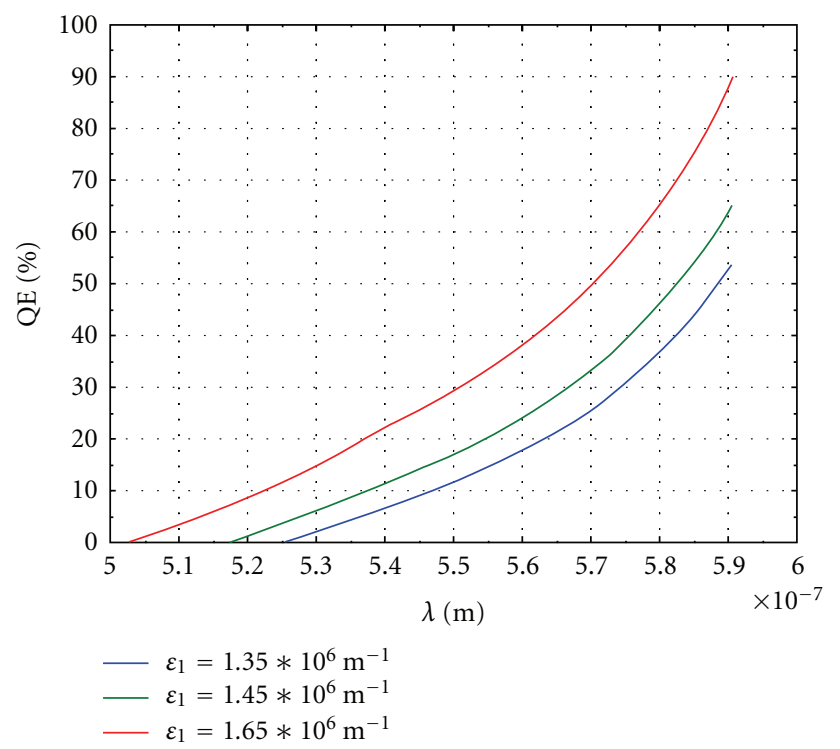

(c)

Figure 7: (a) Variation of the quantum efficiency with the wavelength, for different fractions of Al. (b) Variation of the quantum efficiency with the wavelength, for different solar cell thicknesses. (c) Variation of the quantum efficiency with the wavelength, for different effective field.

cell efficiency based on $\mathrm{GaAs} / \mathrm{Al}_{x} \mathrm{Ga}_{1-x}$ As does not exceed $40 \%$.

Unlike the reflectance, in Figure 9(c) it is observed that the conversion efficiency is strongly correlated with the number of quantum wells up to $N_{w}=30$; over this value the efficiency is saturated in proportion to $N_{w}$. Inside the MQW system the saturation is installed when the road length travelled by light is comparable with the absorption length.

This is a one way to use the HM model. Knowing the materials componence of MQW cell and its optoelectronic properties, for a given geometric configuration the conversion efficiency can be calculated. Obviously the calculation can be repeated varying different geometrical and material parameters in order to determine the optimal configuration, that is, one that maximizes efficiency.

Recently good experimental results were reported in MQW solar cells [21]. The fabricated solar cells based on $\mathrm{In}_{0.3} \mathrm{Ga}_{0.7} \mathrm{~N} / \mathrm{GaN} \mathrm{MQW}$ exhibit an open-circuit voltage of about $2 \mathrm{~V}$, fill factor of about $60 \%$, and an external efficiency of $40 \%-10 \%$ at $420 \mathrm{~nm}-50 \mathrm{~nm}$.

\section{Conclusions}

The results were based on the HM hybrid model of the MQW solar cells; after simulation there were highlighted the following conclusions. 


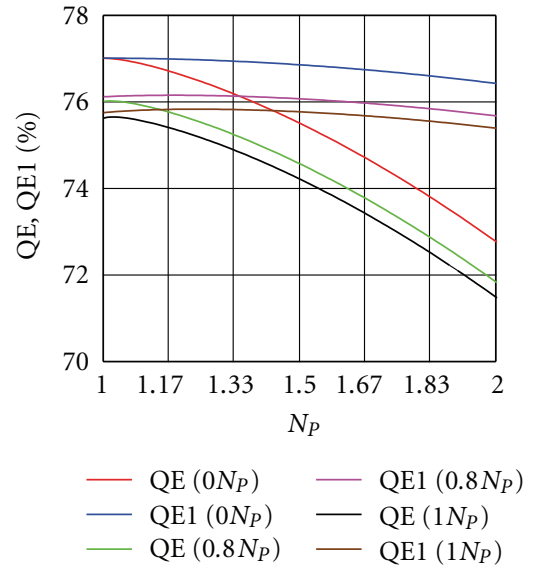

(a)

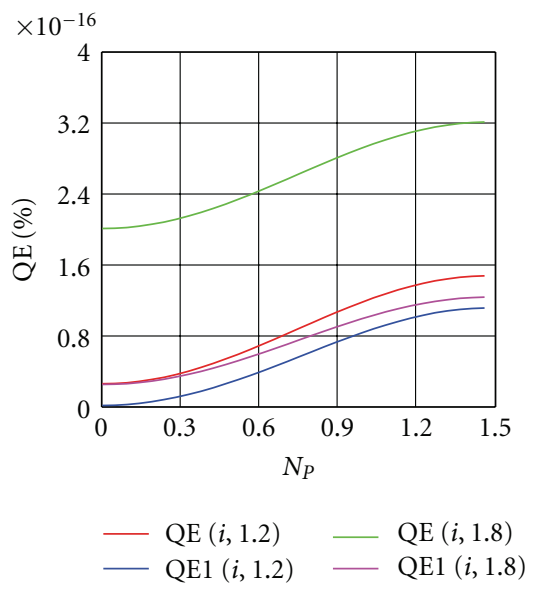

(d)


(b)

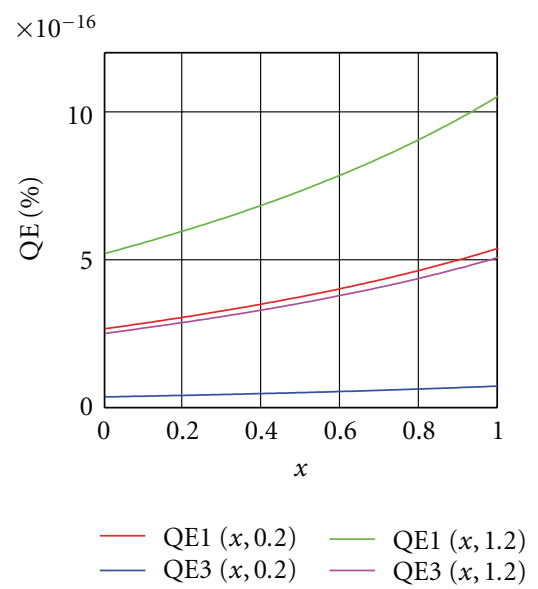

(e)

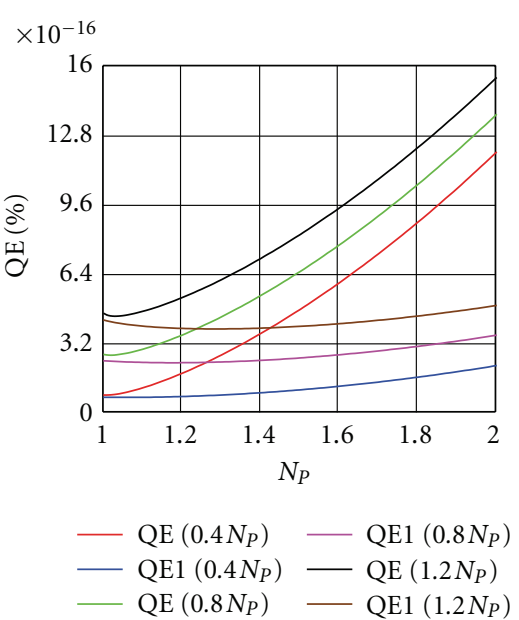

(c)

$\times 10^{-16}$

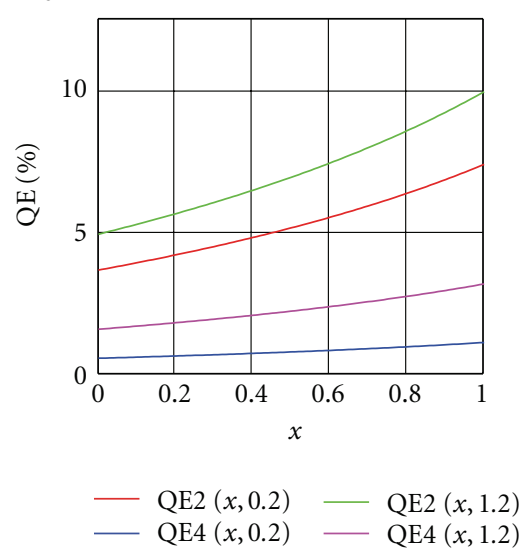

(f)

Figure 8: (a) Quantum efficiency of the transitions between resonant levels for GaAs as a function of the prism refraction index. It is considered the following two main cases: (1) prism angle $\alpha=\pi / 6$ and incidence angle: $i=0$ rad (red curve), $i=0.8$ rad (green curve), $i=1 \mathrm{rad}$ (black curve). (2) prism angle $\alpha=2 \pi / 3$ incidence angle $i=0 \mathrm{rad}$ (blue curve), $i=0.8 \mathrm{rad}$ (violet curve), $i=1 \mathrm{rad}$ (brown curve). (b) Quantum efficiency of the transitions between resonant levels for GaAs as a function of the incidence angle for the ray falling on the prism. (c) Quantum efficiency of the transitions between confinement levels for $\mathrm{Al}_{x} \mathrm{Ga}_{1-x} \mathrm{As}$ as a function of the prism refraction index. (d) Quantum efficiency of the transitions between confinement levels for AlGaAs as a function of the incidence angle of the ray falling on the prism. (e) Quantum efficiency of the transitions between confinement levels for $\mathrm{Al}_{x} \mathrm{Ga}_{1-x} \mathrm{As}$ as a function of the aluminium quantity; prism refraction index is $N p=1.5$. (f) Quantum efficiency of the transitions between confinement levels for $\mathrm{Al}_{x} \mathrm{Ga}_{1-x} \mathrm{As}$ as a function of the aluminium quantity; prism refraction index is $N p=2$.

(i) It could be evaluated the quantum well number effect over the refraction index and reflection losses by evaluation of the quantum well optimal number of the structure.

(ii) The reflectance model proposed by authors could be used to determine variation effect of the quantum well number over the refraction index.

(iii) It was developed an absorption coefficient model which was used for studying the simulation of the MQW solar cells in special weather conditions.

(iv) It was obtained the internal quantum efficiency for the absorption process between the confining levels. (v) The results generated by the model simulator agree with the experimental ones [22].

There were studied several MQW solar cells configurations for optimized values of the optical parameters (reflectance, refraction index, and absorption), so the conversion efficiency could be improved. Although in our study, we considered only rectangular quantum wells, the HM hybrid model allows computing the levels whatsoever the form of the quantum wells is.

New solar devices could be conceived based on optical properties of nanostructured materials $[23,24]$. 


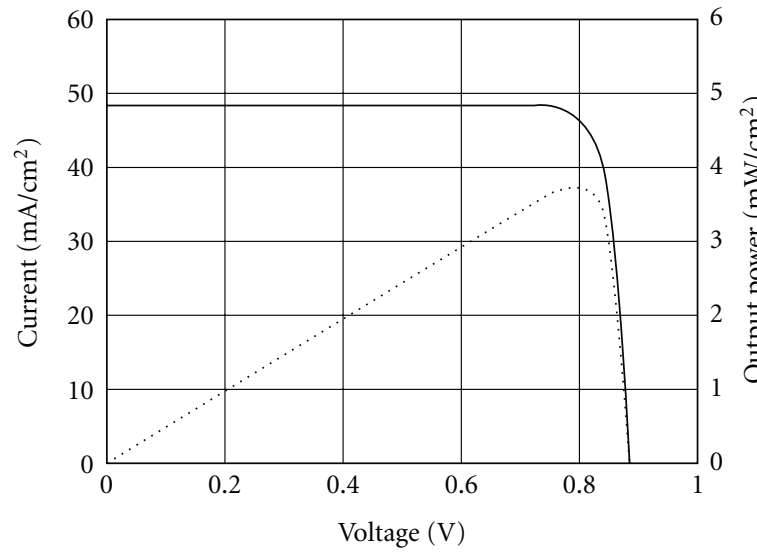

(a)

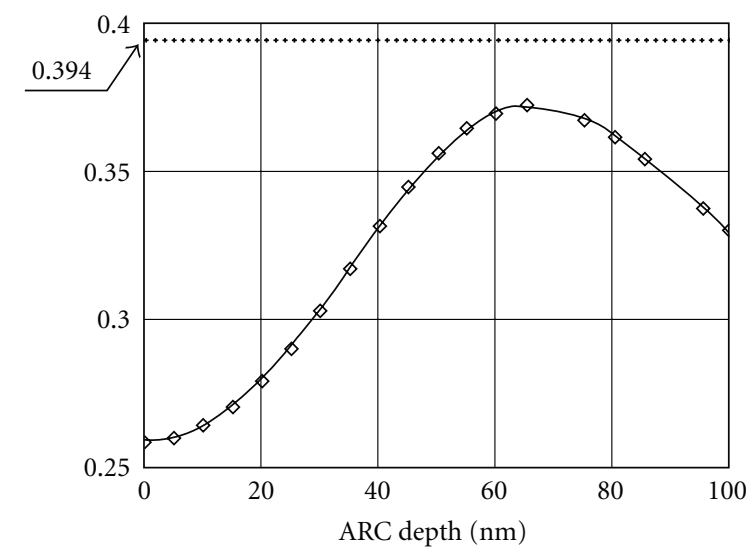

(b)

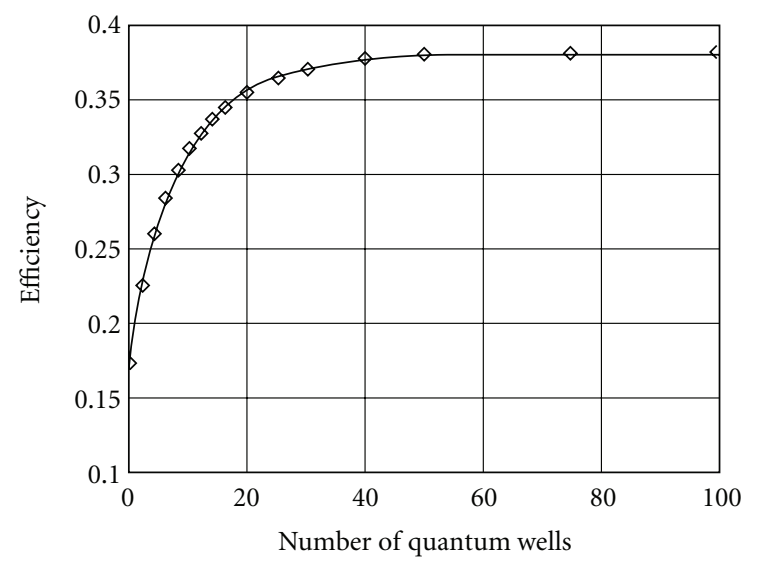

(c)

FIGURE 9: (a) Voltage-current characteristic (line) and the output power (points) of the cell with the following MQW system: $\mathrm{GaAs} / \mathrm{Al}_{0.3} \mathrm{Ga}_{0.7} \mathrm{As}, N_{w}=30, l_{w}=20 \mathrm{~nm}, l_{b}=10 \mathrm{~nm}$ and the antireflecting coating depth $d=64 \mathrm{~nm}$. (b) The MQW cell efficiency depending on the antireflecting coating depth. The dotted line indicates the ideal cell efficiency with zero reflectance. (c) The efficiency of MQW cell based on the number of quantum wells.

QuantaSol [25] is a company form UK which developed firstly quantum wells and quantum dots for solar photovoltaics as well as concentrating solar cells for individual requirements.

\section{Acknowledgments}

Between 2006 and 2009, the NANO-PV (research concerning increase in the efficiency of nanostructured solar cells) project was run in the framework of the Romanian National Programme of Excellence in Research. The project was developed by the research groups in three universities (Polytechnic University of Bucharest, Timisoara West University, and Polytechnic University of Timisoara) which were coordinated by IPA SA. The authors would like to acknowledge and thank their collaborators from the University Politehnica of Bucharest, the West University of Timisoara, and the University Politehnica of Timisoara for the good and fruitful collaboration in developing the NANO-PV project.

\section{References}

[1] K. W. J. Barnham and G. Duggan, "A new approach to high-efficiency multi-band-gap solar cells," Journal of Applied Physics, vol. 67, no. 7, pp. 3490-3493, 1990.

[2] K. W. J. Barnham, "A novel approach to higher efficiencythe quantum well solar cell," in Proceedings of the 11th E. C. Photovoltaic Solar Energy Conference, pp. 146-149, Montreux, Switzerland, 1992.

[3] A. Goetzberger, J. Knobloch, and B. Voss, Crystalline Silicon Solar Cells, Wiley, London, UK, 1998.

[4] J. E. Velazquez-Perez and Y. G. Gurevich, "Charge-carrier transport in thin film solar cells: new formulation," International Journal of Photoenergy, vol. 2011, Article ID 976063, 5 pages, 2011.

[5] J. Ferber, R. Stangl, and J. Luther, "Electrical model of the dyesensitized solar cell," Solar Energy Materials and Solar Cells, vol. 53, no. 1-2, pp. 29-54, 1998.

[6] T. Oda, S. Tanaka, and S. Hayase, "Differences in characteristics of dye-sensitized solar cells containing acetonitrile and ionic liquid-based electrolytes studied using a novel model," 
Solar Energy Materials and Solar Cells, vol. 90, no. 16, pp. 2696-2709, 2006.

[7] G. Smestad, C. Bignozzi, and R. Argazzi, "Testing of dye sensitized $\mathrm{TiO}_{2}$ solar cells I: experimental photocurrent output and conversion efficiencies," Solar Energy Materials and Solar Cells, vol. 32, no. 3, pp. 259-272, 1994.

[8] A. Jüngel and S. Tang, "Numerical approximation of the viscous quantum hydrodynamic model for semiconductors," Applied Numerical Mathematics, vol. 56, no. 7, pp. 899-915, 2006.

[9] W. Shockley and W. T. Read Jr., "Statistics of the recombinations of holes and electrons," Physical Review, vol. 87, no. 5, pp. 835-842, 1952.

[10] L. Fara, R. M. Mitroi, V. Iancu, G. Noaje, and G. Milescu, Modelling and Numerical Simulation of Nanostructured Solar Cells, Punct Publishing House, Bucharest, Romania, 2008.

[11] M. Paulescu, D. A. Vangheli, E. Tulcan-Paulescu et al., Nanostructured Photovoltaic Cells, West University Publishing House, Timisoara, Romania, 2007.

[12] M. Paulescu, P. Gravila, and E. Tulcan-Paulescu, "Optical and electrical modelling of multiple quantum well solar cells," Scientific Bulletin of the "Politehnica" University of Timisoara, vol. 53, no. 66, pp. 114-121, 2007.

[13] M. Paulescu and E. Tulcan-Paulescu, "Assessments on the multijunction solar cells photoelectric efficiency related to the semiconductor band gap and outdoor conditions," Modern Physics Letters B, vol. 19, no. 9-10, pp. 447-457, 2005.

[14] J. A. Hutchby and R. L. Fudurich, "Theoretical analysis of $\mathrm{Al}_{x} \mathrm{Ga}_{1-x}$ As-GaAs graded band-gap solar cell," Journal of Applied Physics, vol. 47, no. 7, pp. 3140-3151, 1976.

[15] J. P. Connolly, Modelling and optimizing $G a A s / A l_{x} G a_{1-x} A s$ multiple quantum well solar cells, Ph.D. thesis, Imperial College of Science, Technology and Medicine, University of London, London, UK, 1997.

[16] J. P. Connolly, I. M. Ballard, K. W. J. Barnham, D. B. Bushnell, T. N. D. Tibbits, and J. S. Roberts, "Efficiency limits of quantum well solar cells," in Proceedings of the 19th European Photovoltaic Solar Energy Conference, pp. 355-358, 2004.

[17] V. Iancu, L. Fara, and R. M. Mitroi, "Quantum confinement modeling and simulation for quantum well solar cells," Annals of the Academy of Romanian Scientists, vol. 1, no. 1, pp. 35-46, 2009.

[18] J. S. Blakemore, "Semiconducting and other major properties of gallium arsenide," Journal of Applied Physics, vol. 53, no. 10, article R123, 59 pages, 1982.

[19] K. W. J. Barnham, I. M. Ballard, B. C. Browne et al., "Recent progress in quantum well solar cells," Nanotechnology for Photovoltaics, pp. 187-210, 2010.

[20] J. P. Connolly, I. M. Ballard, K. W. J. Barnham, D. B. Bushnell, T. N. D. Tibbits, and J. S. Roberts, "Efficiency limits of quantum well solar cells," in Proceedings of the 19th European Photovoltaic Solar Energy Conference, pp. 355-359, Paris, France, June, 2004.

[21] R. Dahal, B. Pantha, J. Li, J. Y. Lin, and H. X. Jiang, "InGaN/GaN multiple quantum well solar cells with long operating wavelengths," Applied Physics Letters, vol. 94, no. 6, Article ID 063505, 3 pages, 2009.

[22] K. W. J. Barnham, I. Ballard, J. P. Connolly et al., "Quantum well solar cells,” Physica E, vol. 14, no. 1-2, pp. 27-36, 2002.

[23] G. E. Jonsson, H. Fredriksson, R. Sellappan, and D. Chakarov, "Nanostructures for enhanced light absorption in solar energy devices," International Journal of Photoenergy, vol. 2011, Article ID 939807, 11 pages, 2011.
[24] M. S. A. Abdel-Mottaleb, J. A. Byrne, and D. Chakarov, "Nanotechnology and solar energy," International Journal of Photoenergy, vol. 2011, Article ID 194146, 2 pages, 2011.

[25] http://www.quantasol.com/. 




International Journal of

Medicinal Chemistry

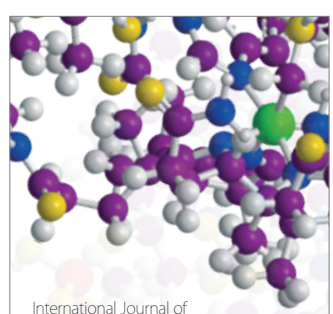

Carbohydrate Chemistry

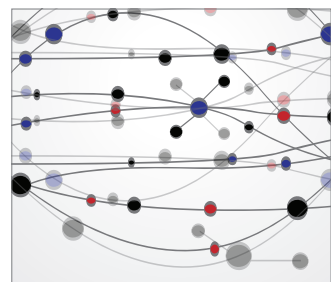

The Scientific World Journal
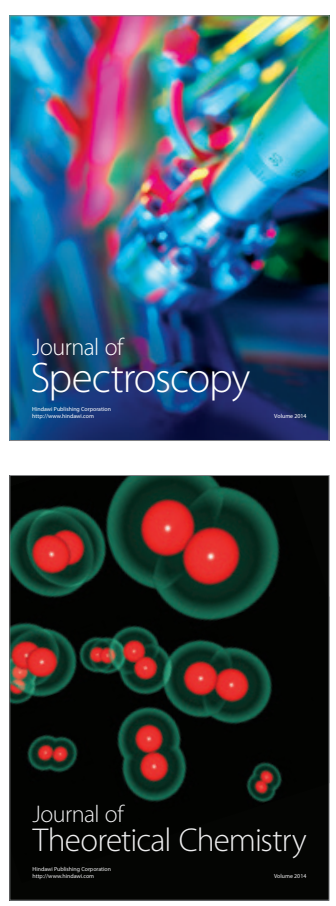


Submit your manuscripts at

http://www.hindawi.com
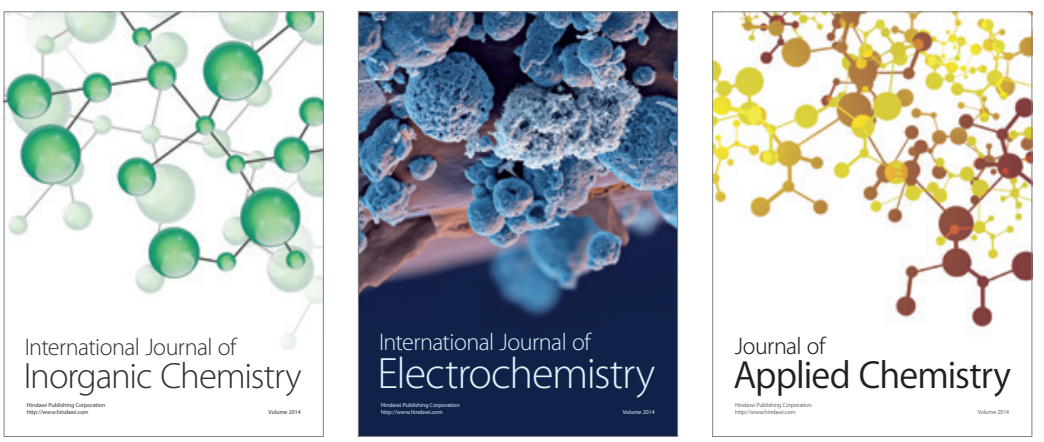

Journal of

Applied Chemistry

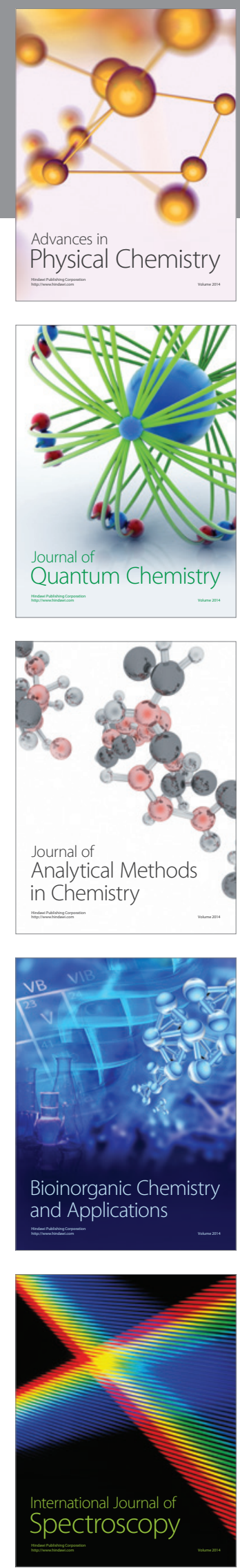